\title{
Transmedia Muppets: The Possibilities of Performer Narratives
}

\author{
AARON CALBREATH-FRASIEUR, University of Nottingham
}

\begin{abstract}
This article examines how the Muppets franchise engages with transmedia narratives, their stories moving fluidly between television, film, comics, the internet and more. Rather than highlight the complexity Henry Jenkins (2006), Elizabeth Evans (2011) and others associate with transmedia, an examination of the Muppets offers insight into a mechanism that allows for simpler coherent connection between texts. The Muppets' ongoing performer narrative challenges the prevailing understanding of transmedia storytelling. As performative characters (singers, actors, performance artists), any text concerned with Muppets, even those in which they act as other characters, becomes part of an overarching Muppet narrative. A high degree of self-reflexivity further supports transmediality, as most Muppet texts contain references to that text as a performance by the Muppets. Thus the comic Muppet Robin Hood and the film Muppet Treasure Island continue the story of the Muppets as further insight is gained into the characters' personalities and ongoing performance history. Examining different iterations of the Muppets franchise illuminates the ramifications of performer narratives for transmedia storytelling.
\end{abstract}

\section{KEYWORDS}

Transmedia storytelling, franchise, narrative, Muppets, multi-platform

For over fifty-five years the Muppets have been appearing in media texts. They began on local television but have spread across most contemporary mediums, with many of these texts part of the over-arching, ongoing Muppet story. This article explores an alternative framework for defining one form of transmedia storytelling. This model suggests a complication in the understanding of transmedia storytelling put forward by Henry Jenkins (2006) and Elizabeth Evans (2011). While the complex interlinked transmedia stories they discuss are the primary contemporary expression of the transmedia storytelling form, I argue that there are other forms of narrative that cross media platforms in meaningful ways which could equally be part of that category. What I call "performer narratives," exemplified by the Muppets, can engage in transmedia storytelling without the level of narrative complexity usually associated with the idea. There may not be a grand design or original universe, but there is a transmedia story nonetheless. Performer narratives allow for multiple iterations of a property to easily fit together as part of an overall story, sometimes functioning as narrative, sometimes as meta-narrative. Self-reflexivity in performer texts enhances the intertextual 
connections, and helps identify the performer narrative at work. To support this concept, I establish that the Muppets are a transmedia property, with an ongoing narrative which continues in multiple formats, new texts building on earlier texts. This ongoing multiplatform story has a broad and loose structure but is nonetheless a form of narrative. I will also suggest other texts and franchises that engage in performer narratives which might fit this model.

For the purposes of a focused case-study for this article, I am defining the "Muppets" as the specific Muppet grouping which originated on The Muppet Show (1976-1981), that has grown and changed over the years and is currently owned by The Walt Disney Company. Therefore, I do not include Sesame Street (PBS, 1969-); though the character Kermit the Frog (Jim Henson/Steve Whitmire) crosses over, it is a very different and now separately-owned property. I am using the term "performer" to mean someone explicitly engaged in presenting entertainment for an audience: acting, dancing, singing, performance art, stand-up comedy and other similar forms.

Henry Jenkins provides a useful definition of the term "transmedia storytelling", and indeed his work seems to be the starting point for most discussions of the concept. Jenkins writes:

A transmedia story unfolds across multiple media platforms, with each new text making a distinctive and valuable contribution to the whole. In the ideal form of transmedia storytelling, each medium does what it does best - so that a story might be introduced in a film, expanded through television, novels, and comics; its world might be explored through game play or experienced as an amusement park attraction. Each franchise entry needs to be self-contained so you don't need to have seen the film to enjoy the game, and vice versa. Any given product is a point of entry into the franchise as a whole. (2006: 97-98)

Jenkins links transmedia storytelling with media convergence, as audiences come to expect varied media experiences that cross over multiple media. Jenkins' prime example of the transmedia story is the Matrix franchise. Animated shorts, comics and games extend the story, and flesh out the world. The game Enter the Matrix (2003) leads directly into the second film and there are certain elements of the film that won't be fully understood unless you have played the game. He also uses the Star Wars and Star Trek franchises as examples. For Jenkins then, transmedia storytelling is purposefully multi-platform and either extends a linear chronological story or expands the storyworld. Elizabeth Evans points to a longer history and broader category of transmediality, but uses a similar model for defining active transmedia storytelling.

In Transmedia Television: Audiences, New Media, and Daily Life, Evans suggests that transmedia storytelling is a component of the more comprehensive term transmediality, which she defines as essentially 'the increasingly popular industrial practice of using multiple media technologies to present information concerning a single fictional world through a range 
of textual forms' (2011: 1). She differentiates transmedia properties which tell stories using multiple media, from transmedia storytelling which is a specific multi-platform practice, suggesting that:

[I]t is essential to map out the differences between contemporary and historical uses of the term. This makes it possible to determine how current developments within the television and film industries are offering new forms of engagement for their audiences whilst refraining from positioning these developments as unique and radical (Ibid.: 20)

Evans tends to follow Jenkins in suggesting that the specific current practice of "transmedia storytelling" is largely the creation of narrative worlds which are explored through multiple formats (for a similar understanding see also Johnson 2009; Long 2007). Evans has delineated current forms of purposeful transmedia storytelling from historical examples that do tell stories using multiple media, but with less 'sense of integration and coherence amongst the individual elements' (2011: 28). While Evans would agree that the Muppets are a transmedia property, she might not see them as an example of "transmedia storytelling": their texts weren't planned that way and the stories don't directly tie together in a chronological manner. They could be seen as being more in line with the historical rather than the current version of transmedia storytelling, which Evans says is about 'creating a coherent, deliberately cross-platform narrative experience' (Ibid.: 20) .

My argument is that the Muppets engage in transmedia storytelling in a way that doesn't require the plan or the direct connections between texts. The Muppets create a world that extends across various texts, there is a history built over time, there is narrative development across texts (just not a traditional chronological story). Disparate texts in multiple media are drawn into the same over-arching story through the use of a performer narrative. Their story as performers weaves all their texts together. To fully understand the Muppet narrative or meta-narrative, the audience would need to be familiar with earlier texts. These texts may not lead into each other in the way Enter the Matrix works, but each text serves to flesh out the fictional Muppet world. I use both narrative and meta-narrative because the story that ties Muppet products together functions in different ways in their various texts. For instance, in their three TV series, the performer narrative acts as the narrative of the text, each focuses on the characters performing in a show, combining onstage acts with backstage drama. On the other hand, in their adaptation films, the primary narrative is the fictional work being adapted, while the Muppets performer narrative functions as a meta-narrative, that of Muppets making a movie. Thus textual narrative and meta-narrative both contribute to the overall Muppet story. Because of the different registers involved I primarily use "narrative" to describe the Muppet story, unless discussing a specific meta-narrative instance. Before moving on to my concept of performer narratives, it is important to establish that the Muppets are a transmedia property, appearing in a particularly wide range of formats. 
Volume 5, Issue 2

September 2012

\section{Muppets as transmedia property}

The Muppets, as defined earlier, appear in a wide variety of forms, perhaps more than most other media franchises. I would argue that the Muppets have texts in at least eighteen format categories (Table 1), though these could potentially be divided and grouped differently. I have separated them according to differences in production, distribution and academic approaches. In addition to these official texts, there are numerous fan-produced materials in a variety of forms. Most of these categories are self-explanatory formats, but the category of peripheral or paratextual material needs some explanation.

\begin{tabular}{|l|l|l|}
\hline Screen Material & Print Material & Other \\
\hline 7 theatrically-released films* & $\begin{array}{l}\text { Magazine: Muppet Magazine } \\
(1983-89)\end{array}$ & $\begin{array}{l}\text { Peripheral or Paratextual } \\
\text { (including screen material)* }\end{array}$ \\
\hline $\begin{array}{l}\text { 4 TV series: The Muppet } \\
\text { Show, The Muppet Babies, } \\
\text { The Jim Henson Hour, } \\
\text { Muppets Tonight* }\end{array}$ & $\begin{array}{l}\text { Books (incl. children's, self- } \\
\text { help (parody), } \\
\text { 'autobiography, photo, } \\
\text { annuals and more) }\end{array}$ & $\begin{array}{l}\text { Amusement park attractions } \\
\text { (including screen material)* }\end{array}$ \\
\hline $\begin{array}{l}\text { TV specials/TV movies } \\
(13+)^{*}\end{array}$ & Comic books & Albums/CDs* \\
\hline Online Videos/Websites* & Newspaper serial comics \\
\hline $\begin{array}{l}\text { TV/Celebrity appearances } \\
\text { (Non-Muppet texts)* }\end{array}$ & $\begin{array}{l}\text { Visual material: art, posters, } \\
\text { calendars }\end{array}$ & Toys, Merchandise, Clothing \\
\hline Video Games* & & Livearances* \\
\hline Original Video/DVD* & & \\
\hline Commercials* & & \\
\hline
\end{tabular}

*Format includes original performances by the Muppeteers in many instances.

Table 1: Muppet product formats

My use of "peripheral" or paratextual material here is a variation on Jonathan Gray's paratext (Gray 2010). While Gray includes as paratext all the material that surrounds a text which influences our understanding of said text, I am using it here to indicate a particular subset of these materials. Gray includes other categories I've listed, such as toys, CDs or posters, within the paratext category. However, in the Muppets case these are often primary texts in their own right, thus I have chosen to separate them out. As an example, in addition to CDs reproducing music from film or TV, the Muppets have original CDs, such as Kermit Unpigged (1994) or Muppet Beach Party (1993) which are stand-alone products, original 
audio performances by the Muppeteers. Notably, both also contain narrative material in the form of dialogue between songs. Additionally, even the LP album The Muppet Show (1977) which contained mostly songs from the show, also contained interstitial skits of original material for the album. Many of these albums then are not paratexts for a particular primary text. However, there are other Muppet paratexts surrounding the shows and films, such as ads, DVD special features, etc..

Muppet paratexts, different from many other properties' paratexts, are often original performances by the Muppets. Commentary on DVDs is sometimes done in character. Muppet characters often guide "behind the scenes" shorts and make celebrity appearances supporting products. Therefore, even paratexts often become interesting sites of Muppet performance, and a continuation of their narrative. Striking examples of paratextual performance are the improvised promo spots for The Muppet Show made available on the DVD release of the show's first season. These are improvised moments between Muppet characters, amusing and worthy in their own right. This kind of ephemeral media would not normally be classed as a primary text, yet they are original performances and certainly of value to a Muppet fan. The issue of originality is key to understanding other Muppet products as well; in their originality texts are made out of items that might otherwise be seen as merchandise. In the category of posters, for instance, there are standard promotional posters, such as a Muppet Christmas Carol (1992) promo poster, which work as paratexts around a particular text. However, the Muppets also have a tradition of parody images used for posters, books and calendars - often photographed using poseable photo-puppets made by the same people who make the Muppets for the screen. These images are not linked to any Muppet screen text; instead, they suggest Muppet adaptations of other texts. Unlike some other merchandise, these images have often been designed in-house by the Jim Henson Company or later by Muppet Studios LLC. These items, then, could be interpreted as just merchandise or as original Muppet visual texts.

If we were to take the view that transmediality has primarily been a means of brand extension, marketing and merchandising, maybe some texts such as books by external authors or poster images could be considered secondary. However, since eleven of these eighteen official product areas involve original performances by the Muppeteers, they are equally Muppet texts; it wouldn't be appropriate to consider them secondary or ancillary to some primary text. Caldwell, drawing on others, has suggested that secondary and tertiary television texts have migrated towards primary status (2006: 103), and in the context of the multi-platform media franchise, this concept can be extended to other media as well. With the Muppets in particular, from very early on there was an effort to make primary texts in whatever area they were exploring, signalled in part through self-reflexivity, which I will discuss further below.

So Muppets are a transmedia property, but do they engage in transmedia storytelling? If we view storytelling as a linear, presented chronology of related events, then perhaps not. As mentioned above, the links between Muppet texts are not like the commonly used example of 
the Enter the Matrix video game which leads directly into the second Matrix film, and contains relevant information referenced but not included in the film. Even The Muppet Movie (1979), which was filmed and released while The Muppet Show was ongoing, has no events directly tied to the show. But we learn more about the characters of the show and their history in the film. Though there is minimal direct event correlation between different texts, there is still a story being told across their various texts. It's a story of characters, friendships, romance, personal growth, and an expansion of the Muppets diegetic worldfitting with Jenkins' understanding of transmedia storytelling as world-building. Moreover, through the use of a performer narrative, it allows basically all texts to be easily incorporated into the overall picture, even when the Muppets aren't playing themselves.

\section{Performer narratives}

So what do I mean by performer narrative? The Muppets as characters are positioned as performers: actors, singers, musicians, dancers, performance artists. Their overarching narrative revolves around the act of performing. Their TV series have all been about putting on a show, with the backstage elements reinforcing the idea that onstage performances are designed by the characters. Their other texts involve performing in some capacity, either explicitly or implicitly. A performer narrative involves performer characters, engaged in acts of performance as well as non-performance character development. Performances often involve character information, creating a meta-narrative through the performance. Choice of material, behavioural traits, skill-level - all these things tell us about the performer during performance, in addition to specific narrative information that may be present. Selfreflexivity is often used to signal the performance as performance, and help build this metanarrative.

As an example, the character Gonzo (Dave Goelz), a self-styled "performance artiste," is defined primarily through his performances. His acts tend to be bizarre mixtures of high and low culture, often with an element of death-defying daring. Every act he does informs our understanding of the character, sometimes just another example of avant-garde sensibilities or weirdness, but sometimes more than that. On several episodes of The Muppet Show and in films he is given particularly sad and deep songs to sing, showing a more empathetic and sentimental level to his personality. "I'm Going to Go Back There Someday" which he sings in The Muppet Movie is a very wistful heartfelt song about belonging, friendship, and loss. It emphasises his soulful side. Like other Muppet characters Gonzo changed and grew across various Muppet texts. Traits which may now seem inherent to the character, such as Gonzo's love for chickens, actually developed over time. When he plays a character, such as the Sheriff of Nottingham, Rumplestiltskin, or the Mad Hatter, he brings his own particular manic energy and strange tastes to that character, but further aspects of his own persona also continue to develop. 
When a Muppet text tells a non-Muppet story, such as in their adaptation films, the text can be thought of as being a Muppet performance, the Muppets making a film, playing other characters. In some instances there is explicit positioning as Muppet performance, in other cases the use of self-reflexivity highlights the performance. In The Muppet Christmas Carol, their first literary adaptation film, the story of the film is Dickens' A Christmas Carol, but the meta-narrative is that it is a Muppet performance of $A$ Christmas Carol, even the opening credits read: 'Starring Kermit the Frog as Bob Cratchit,' and so on, with Gonzo as Charles Dickens (serving as onscreen narrator). Furthermore, the film expands the Muppet story and world, while at the same time staying fairly faithful to the original story. The clearest instance is that the film creates and develops the friendship between Gonzo and Rizzo the Rat (Steve Whitmire) that would become the core Muppet relationship of the 1990s. During that decade, they replaced Kermit and Fozzie Bear (Frank Oz) as the key protagonists in Muppet stories. So while the film's plot isn't about the Muppets, it still works as part of the overall Muppet story.

The Performer narrative makes all the CDs, the movies, the specials, into more expressions of Muppet performance. Their online videos, even when just songs, draw on character knowledge and are positioned as the Muppets themselves adapting to a New Media setting, whether it is Gonzo posting chickens performing Strauss on YouTube, or a conference call that degenerates into Queen's 'Bohemian Rhapsody'. These texts are Muppets performing for the Internet. The performer narrative even links non-Muppet texts into the overall story, in that Muppets make celebrity appearances on talk-shows, game shows, even "reality" shows, in character. Thus the role that would normally be reserved for real world "stars" becomes an extension of the Muppets fictional world. Their fiction and our reality are conflated, extending their narrative into the general celebrity system.

Indeed, one major complication for the discussion of the Muppets performer narrative comes in the concept of fictional worlds that has been associated with transmedia storytelling (in Evans; Jenkins; Johnson; Long). The problem is that the world of the Muppets is so highly conflated with our own, that it is hard to distinguish texts that detail their "world". Their story is very similar to that of real world stars and celebrities, sometimes playing out in a similar fashion to a fabricated star persona. The fictional performer narrative connects texts in a similar way. When dealing with a completely fictional world it is usually obvious when a text is allowing audiences to explore that world. With the Muppets it is hard to tell where our world ends and theirs begins. Consider as a hypothetical example, a Deborah Harry biography might dedicate a paragraph to her performance on The Muppet Show, her duet with Kermit. This would be part of her personal history, an expression of her star persona, her story as a star, but not fiction. On the Muppet side, this story becomes part of the fiction. Kermit performed a duet with Debbie Harry. This moment is part of Muppet history, part of the Muppet narrative. The reverse situation is similar. When a celebrity goes on a talk show promoting a film, this may be paratextual material (and thus may affect our understanding of the text) but it is not an extension of the narrative; the celebrity is an actor, not the character. 
When Kermit goes on a talk show promoting The Muppets, he is the same entity that appears in the film, "actor" and character, there is no distinction, so the non-Muppet talk show becomes part of the overall narrative of Kermit.

\section{Is there an ongoing Muppet narrative?}

Still considering the difference between transmediality and transmedia storytelling we have to ask, does a Muppet story travel across texts? Muppet texts certainly lean towards the episodic, existing to some degree as separate entities. So it could be seen as characters or brand encompassing different texts, a multi-platform property, rather than as an example of an over-arching transmedia story. However, I would argue that it is a story, a narrative, just a different kind of narrative. The story of the Muppets is of performers putting on shows or performing in various formats: their relationships, personal growth or change, and performing. Though their texts are somewhat episodic, there is also an element of seriality in them.

Angela Ndalianis, in her work on Neo-Baroque television, argues that certain television series blur the line between series and serial (see also Neale and Krutnik [1990] regarding the same concern in television comedy). She writes:

The series (which consists of a succession of self-contained narrative episodes that progress in a sequence) and the serial (which comprises a series of episodes whose narratives resist closure and continue into the next episode(s) within the sequence) have increasingly collapsed into each other, so much so that, in more recent times, it has become difficult to distinguish one from the other. (2005: 84)

One of the ways this blurring happens is through character and relationship development across series that might otherwise be seen as episodic. Ndalianis, drawing on Omar Calabrese's work, writes that this collapse between series and serial can be seen in:

... the relationship between episode time (which was closed, contained and concluded), series time (which was open, had no narrative goal and presented an infinite time frame) and narrated time (which was also open in that characters developed and there was a greater flow and dependence on preceding episodes, thus reflecting features of the serial) (Ibid.: 93).

If we, as Ndalianis, can take character development as indicative of serial storytelling, a continuing story, then surely the connections between Muppet texts also adds up to a continuing story. Characters develop and change, relationships develop and change. There are areas of resisted closure, such as the will-they-won't-they relationship between Kermit and Miss Piggy (Frank Oz). These things travel across texts, and a knowledge of previous iterations would certainly enhance audience understanding of a given text. Kermit and Miss 
Piggy as the Cratchits in A Christmas Carol and their interactions with their "children" are amusing, but more entertaining if you are aware of their relationship dynamics, and more significant if seen in the context of their on-going "will-they-won't-they" scenario.

There are Muppet instances that are closer in linearity to Jenkins' understanding of transmedia storytelling. One instance comes in the fifth season of The Muppet Show. Deborah Harry is the guest, and has requested to sing a song about rainbows. Kermit hints that he is upset that she hasn't included his rainbow song on her list of potential songs. To fully understand the humour of the moment requires that you be familiar with Kermit's song 'Rainbow Connection', either from The Muppet Movie or from radio play. While these kinds of direct reference aren't common (there are a few other brief references to the film on the show), there are other moments of "history" displayed on the show, with characters reminiscing about past guest stars or sketches, and even reference to external texts such as when Kermit talks to Julie Andrews about a television special they worked on together. There is a sense of history, a sense of progression, of ongoing story.

\section{Muppets and self-reflexivity}

I've suggested that this story that carries across the various Muppet texts is constructed in part through self-reflexivity. Self-reflexivity has always been a part of Muppet media, and it plays a significant role in maintaining the performer narrative in Muppet texts. It is used to signal the idea that each text is a performance by the Muppets, sometimes subtly, sometimes very explicitly. Self-reflexive practice in their films highlights the text as performance. By signalling that a movie is a movie, they position themselves as actors within a film. This is made most explicit in the first two Muppet films. The Muppet Movie is bookended by the Muppets screening a movie that they have made about their origins, and this movie within the movie is the main body of the film. There is also a moment in the film, when rather than engage in exposition Kermit simply gives other characters a copy of the film script to catch themselves up.

The first film is a story about the Muppets, meant to more or less reflect their diegetic reality. In their second film, The Great Muppet Caper (1981), the characters and relationships are present, but in the main plot they are not themselves per se, and particularly not positioned as performers: Kermit is a journalist and Miss Piggy an administrative assistant. The film is positioned from the start, however, as a film being made by the Muppets in which they play characters. The movie begins with Kermit, Fozzie Bear and Gonzo in a hot air balloon watching and commenting on the opening credits of the film. Then an expositional song sets up the premise of the film, and Kermit explains the characters they are playing in this Muppet-made movie.

Later films are not as explicit as this, but self-reflexive commentary signals a similar construction to the audience. As an example, in Muppet Treasure Island (1996), when Billy Bones (Billy Connolly) dies, Rizzo questions, 'He died? And this is supposed to be a kid's 
movie!' Moments like this are common in Muppet films. One of the stronger examples of self-reflexivity and a multi-layered performance approach to a text was in the 2005 TV movie The Muppets' Wizard of $\mathrm{Oz}$. Kermit has three roles in this text. First he appears as his narrative self: Kermit is travelling around the US auditioning singers to perform with the Muppets and Dorothy Gale (Ashanti) wants to audition. Second, he appears in $\mathrm{Oz}$ as a character: the scarecrow. Then, during the climactic fight scene the movie suddenly cuts to an office where Quentin Tarantino is pitching to a non-narrative or meta-narrative Kermit ideas for resolving the fight sequence. Exposing this meta-narrative, the text is firmly positioned as a Muppet created performance, harkening back to The Muppet Show, putting Kermit in a producer role, suggesting that the Muppets are even part of the business side of production. Moments like these consistently suggest to the viewer that each text is a text made by Muppets.

One important aspect of Muppet self-reflexivity is that it tends to be medium specific. Whatever the format the Muppets are in, there is usually an engagement with that format, there is some degree of deconstruction - not necessarily in all cases, but in many, and in enough to create this over-arching performer narrative to tie together all their productions. By making explicit the medium, they position the text as a performance by the Muppets in that medium. Looking back to Jenkins, he suggests that in transmedia storytelling each format must do what it does best, there is a certain uniqueness to each media. Through selfreflexivity the Muppets make their performance in each media distinct and specific to that media.

As examples of this approach, consider two examples from audio texts. Many of the Muppet music albums have original songs (not taken from TV or film) as well as sketches between songs. Some of the dialogue on these albums makes the medium explicit. Kermit's tap dance rendition of 'Happy Feet' on an early Muppet album isn't just a reproduction of the song from the show, it is recontextualized through commentary from Waldorf (Jim Henson) who says, 'On the show that wasn't funny, but on a record it doesn't even make sense' (rereleased on Muppet 2002, Track 12). In another short record sketch Fozzie proposes a totally inappropriate act for the record. He performs 'hat tricks,' which are, obviously, visual. Kermit says, 'well Fozzie, somehow it doesn't quite make it on a record.' Fozzie replies, 'what? You couldn't hear my ears wiggle?' (Ibid., Track 3). By including this character commentary on the album, the record becomes a new Muppet experience, Muppets doing an audio performance.

Muppet online videos provide another example of medium-specific self-reflexivity that highlights performance. Beaker's 2010 YouTube video Beaker's Ballad, positions itself as Beaker (Steve Whitmire) creating an amateur video for YouTube. He is sat behind a keyboard, apparently in his candlelit room, playing guitar and singing Kansas' 'Dust in the Wind' (Muppets Studio). The sketch quickly descends into chaos as "viewers" begin commenting on the video, with the comments appearing as "annotations" on the video itself (this is a bit of poetic licence on the part of Muppet Studios: YouTube viewers cannot 
actually "annotate" another user's video, nor would it occur live obviously). The initial comments are entirely negative: 'fail' 'Disasterpiece' 'teh lose' [sic]. Beaker's struggle to remain visible behind the multiplying annotations leads to a fire, with the comments adjusting accordingly: 'XD! Fire!' 'Epic, fire-y win' 'MOAR FIRE!!!!' and finally as Beaker disappears from screen, 'is he died?' [sic]. After Beaker stumbles out from the smoke, now in front of all the annotations, the video cuts to the Muppet hecklers, Statler (Steve Whitmire) and Waldorf, sat at their own computer, discussing whether to 'Digg' the video. This video directly engages with online video conventions (amateur song videos, commenting, Internet slang, Digg-ing), parodying and deconstructing the form. But it also tells the audience more about Beaker, it suggests that he is making amateur online videos, it is the first time ever that we see his personal space. It expands our understanding of him, and the Muppet diegesis. What is ostensibly just a performance of a song becomes part of the Muppet story, through expansion of character and self-reflexive engagement with the medium. ${ }^{1}$

Self-reflexivity carries over to Muppet written texts, that some might consider secondary. Boom! Studios' Muppet comic books contain a number of references to the comic book format, addressing the differentiation of the medium. The first issue of The Muppet Show Comic Book begins with the Newsman reporting that, "we are receiving unconfirmed reports that The Muppet Show is back on the air in a new format, that of the so-called "comic book". Viewers are requested to make the necessary adjustments.' The page is drawn as turning before he can finish the report, much to his consternation (Langridge 2009: 1). On the next page, Statler and Waldorf once again fill their heckling role saying:

Statler: A Muppet Show comic book! Oh no, they're back to corrupt a whole new medium.

Waldorf: Why's it called a medium?

Statler: Cause it's rarely well done! Ho, Ho! (Ibid.: 3)

These moments make explicit the comic as comic, emphasising medium specificity. Through this kind of medium-specific self-reflexivity it makes explicit a performer narrative in action, the Muppets are performing within a comic book setting. While The Muppet Show Comic Book series followed the format of The Muppet Show (onstage performances framed by backstage drama), Boom! Studios also created mini-series with Muppets cast in adapted stories. In these comic books some self-reflexive moments highlight the performative nature of the fiction. In Muppet Robin Hood, at one point the characters look at the "script" to determine what they should do, and even attempt to track down the comic's author to change the story. Another moment emphasises the idea that the Muppets are playing characters in the comic, when Kermit's nephew Robin explains he had to be given the name 'Squirt' so as not to clash with Robin Hood the character (Beedle 2009: n.p.). Thus even in print formats, self-reflexivity remains a component of Muppet texts. 
The high degree of self-reflexivity in Muppet material continues into current projects. The first three trailers for the 2011 release of the film The Muppets were parody teaser trailers. In the third of these (a Green Lantern parody), about halfway through, the flow of the trailer stops to ask, 'is this another Muppet trailer parody? Why don't we just show a real trailer? I mean, what are we hiding?' This kind of deconstruction is Muppet tradition, part of the way they've always engaged with whatever format they are in (in this case: trailers), and it furthers the performer narrative, positioning itself as Muppets making a trailer.

\section{Other performer narratives}

If the Muppets were unique in using the "performer narrative" it wouldn't be a particularly useful framework, but it can be applied to other properties with similar performer narratives. The Muppets are unusual but not unique and it is worth briefly considering other performerbased properties. Looney Tunes have something of a performer meta-narrative in some of their cartoons and emphasised further in feature films. Disney has retroactively tried to create one with the film Who Framed Roger Rabbit (1988), shows like House of Mouse (Disney Channel, 2001-2) and in Disney theme parks, particularly Disneyland's Toontown. These texts and locations position animated characters as actor-characters, who perform in various other texts. The performer narrative is a loose narrative and allows for many possible stories to all fit under the larger meta-narrative.

They don't have the long history of the Muppets but the live performances and CDs by the casts of Flight of the Conchords (HBO, 2007-09), Glee (Fox, 2009-) or The Mighty Boosh (BBC Three, 2003-07) could be considered part of each property's meta-narrative. Glee and Mighty Boosh live performances are done partly in character, and at least in the latter case contain new material. Performing live as a band, Flight of the Conchords appear as performative versions of themselves, but also use this approach on the cable show. One of the things the Muppets do as part of their world building is to actively conflate their world with the real world. Real world celebrities enter into Muppet texts, and Muppets engage in real world celebrity. Flight of the Conchords does some of the same conflation between story and reality, using the real names of the protagonists, and some biographical detail, mixing performer narrative and performer reality. Are CDs and live shows just re-production or is it an extension of the performer story? Music is significant in all these texts, as it lends itself to multi-media performance (albums, concerts, music videos, etc.). Similar performer narratives might be found in earlier music-related texts such as The Monkees (NBC, 1966-8), or the films starring The Beatles. All these transmedia properties use some degree of performer narrative, suggesting that this model is useful beyond a study of the Muppets.

\section{Conclusion}


While the Muppets offer a particularly strong example of a narrative that is expanded across multiple platforms through the use of a performer narrative, there are other properties that might be explained using a similar model. Performance-based characters allow texts in a wide-range of formats to contribute to an over-arching story. I have shown that the Muppets utilize a performer narrative to engage in transmedia storytelling, making texts in multiple formats part of an over-arching Muppet narrative, and that they use self-reflexivity to signal and enhance this ongoing performer story.

The Muppets are a transmedia, multi-platform property. It is clear that there is an ongoing story of the Muppets which functions either as narrative or meta-narrative depending on the text, and that this narrative is continued in a variety of media. The question then becomes, is there value in describing this as 'transmedia storytelling'? Or should that term be reserved for a very specific industrial strategy? Jenkins' oft-quoted model offers too limited a view of the history of transmedia storytelling, focusing too much on the current climate of convergence. The Muppets, among other properties, suggest that it has a longer history than he posits. Evans, on the other hand, acknowledges this history, offering the wider term transmediality, then goes on to demarcate the term 'transmedia storytelling' as a particular recent industrial practice. If we accept this concept of the term, then the Muppets and other performer narratives (that do not engage in these specific practices) would fall into the general category of transmediality. The danger there I think is that this is too restricted a view of what constitutes storytelling or narrative. Certainly the performer narrative acts as a distinctive form of multi-platform media practice, and in the Muppet case it seems to extend and explore the world of the Muppets across a wide variety of media. The Muppets franchise and the performer narrative should at least be considered as a form of transmedia storytelling.

\section{References}

Beedle, T. (2009) Muppet Robin Hood. TPB ed. Los Angeles: Boom! Kids

Caldwell, J. (2006) 'Critical Industrial Practice: Branding, Repurposing, and the Migratory Patterns of Industrial Texts', Television \& New Media, 7, May: 99-134

Evans, E. (2011) Transmedia Television: Audiences, New Media, and Daily Life. London: Routledge

Frawley, J. Dir. (1979) The Muppet Movie. USA, UK: Henson Associates

Gray, J. (2010) Show Sold Separately: Promos, Spoilers, and Other Media Paratexts. New York: NYU Press

Henson, B. Dir. (1992) The Muppet Christmas Carol. USA, UK: The Jim Henson Company

Henson, B. Dir. (1996) Muppet Treasure Island. USA, UK: The Jim Henson Company

Henson, J. Dir. (1981) The Great Muppet Caper. UK: Henson Associates 
Jenkins, H. (2006) Convergence Culture: Where Old and New Media Collide. London: New York University Press

Johnson, D. (2009) Franchising Media Worlds: Content Networks and the Collaborative Production of Culture. University of Wisconsin - Madison

Kermit Unpigged. (1994) Jim Henson Records/BMG Kidz

Langridge, R. (2009) The Muppet Show Comic Book. Issue 1. Los Angeles: Boom! Kids Long, GA. (2007) Transmedia Production: Business, Aesthetics and Production at the Jim Henson Company. Massachusetts University of Technology

Muppet Beach Party. (1993) Jim Henson Records

The Muppet Show. (1977) Arista Records

The Muppet Show Episode 2.17 Julie Andrews. (1977) Henson Associates

The Muppet Show Episode 5.9 Debbie Harry. (1980) Henson Associates

The Muppet Show: Music, Mayhem and More! The 25th Anniversary Collection. (2002) Rhino Records

The Muppet Show: Season One. (2005) Buena Vista Home Entertainment

Muppets Studio. The Muppets: Beaker's Ballad. February 2010. Available from http://www.youtube.com/watch?v=EAtBki0PsC0 [Accessed 30.06.11]

Ndalianis, A. (2005) 'Television and the Neo-Baroque' In Hammond, M., and Mazdon, L., (eds) The Contemporary Television Series, Edinburgh: Edinburgh University Press, pp.83101.

Neale, S., and Frank Krutnik. (1990) Popular Film and Television Comedy. London: Routledge

Thatcher, K. Dir. (2005) The Muppets’ Wizard of Oz. USA: Jim Henson Company

\footnotetext{
${ }^{1}$ It should also be noted that the Muppets have on occasion also taken self-reflexivity to its endpoint, in that they not only highlight film as film, comic as comic, but also Muppet as puppet. The instances are uncommon but they do exist. Kermit in particular has, in several Muppet texts, exhibited the knowledge that he and the others are puppets.
} 